\title{
The effect of forage source and supplementary rumen protected methionine on nitrogen balance in autumn calved dairy cows offered a low crude protein diet
}

S J Whelan, F J Mulligan, J J Callan, K M Pierce

UCD School of Agriculture, Food Science and Veterinary Medicine, Dublin, Ireland

Email: stephen.c.whelan@ucd.ie

Introduction The apparent inability of the dairy cow to efficiently convert feed nitrogen (N) into useable milk $\mathrm{N}$ results in large quantities of ingested $\mathrm{N}$ being excreted and lost to the environment as $\mathrm{NH}_{3}$ and $\mathrm{N}_{2} \mathrm{O}$, the latter a potent green house gas. Feeding low crude protein (CP) diets has been shown to reduce excreted N (Mulligan et al., 2002) however it has been suggested that for such diets the essential amino acid methionine may become limiting to production (Write et al., 1998). Alternative forages to grass silage (GS) such as maize silage (MS) are becoming increasingly popular in the diet of dairy cows (Burke et al., 2007). MS has also been shown to improve the efficiency of $\mathrm{N}$ utilization relative to GS. The purpose of this experiment was to determine the effects of (i) forage source (GS vs. MS) and (ii) supplemental rumen protected methionine on $\mathrm{N}$ partitioning and performance of lactating dairy cows.

Materials and methods 4 primiparous and 4 multiparous cows were offered 1 of 4 dietary treatments in a $2 * 2$ factorial, Latin square design. Cows were 120 days in milk at the beginning of the experiment. The diets were grass silage (GS), grass silage with methionine (GSM), maize silage (MS) and maize silage with methionine (MSM) Diets were formulated such that the forage component consisted of $81 \%$ grass silage and $19 \%$ maize silage on a DM basis or $83 \%$ maize silage and $17 \%$ grass silage on a DM basis, with or without supplementary rumen protected methionine (Metasmart ${ }^{\circledR}$ ), The concentrate component consisted of rolled barley, beet pulp, soybean meal and a mineral/ vitamin premix, the forage to concentrate ratios were 52:48 and 63:37 for the grass silage based and the maize silage based diets respectively. All diets were designed to meet the UFL (18.71UFL day ${ }^{-1}$ ), PDI (1950g day ${ }^{-1}$, PDIN 1959g, PDIE 1950g, PDIA 897g) and lysine (7.1\% of PDI) requirements for production $\left(30 \mathrm{~kg} \mathrm{day}^{-1}, 4.1 \%\right.$ fat, $3.3 \%$ protein). GS and MS were calculated to be deficient in methionine $(1.78 \%$ of PDI) whereas GSM and MSM met the requirements $(2.3 \%$ of PDI) of the animal. Diets were offered daily as a total mixed ration. Total faecal and urine collections allowing N-balance calculations were performed for the last 5 days of a 10 day period; animals were housed in metabolic stalls to facilitate separate collection of excreta and milked in-situ. Milk yield, feed refusals, urine, faeces and feed offered were weighed and sampled each morning for analysis of N. Data were analysed using proc GLM of the SAS.

Results There was no significant difference found for either effect of forage source, supplementary rumen protected methionine or interactions between both on milk production or the partitioning of $\mathrm{N}$ between milk and excreta by the dairy cows on this experiment Urea N levels in bodily fluids (UUN, MUN and BUN) were significantly reduced in cows offered grass silage based forages; there was no significant effect of methionine supplementation on these parameters.

Table 1 Effect of forage source and supplementary methionine on N partitioning in autumn calving dairy cows

\begin{tabular}{lllllllll} 
& & Forage Source & & \multicolumn{3}{c}{ Methionine } & \multicolumn{3}{c}{ Significance } \\
& Grass Silage & Maize Silage & LSM \pm sem & N & Y & LSM \pm sem & Forage Source & Methionine \\
\hline Milk Yield & 20.23 & 20.29 & 0.666 & 20.17 & 20.36 & 0.666 & 0.9528 & 0.8447 \\
DMI & 19.13 & 20.23 & 0.716 & 19.71 & 19.65 & 0.717 & 0.285 & 0.995 \\
N intake & 0.422 & 0.460 & 0.0128 & 0.447 & 0.435 & 0.0128 & 0.0426 & 0.5371 \\
Faecal N & 0.186 & 0.201 & 0.0100 & 0.193 & 0.194 & 0.0101 & 0.3125 & 0.9554 \\
Urine N & 0.123 & 0.131 & 0.0055 & 0.131 & 0.123 & 0.0056 & 0.3018 & 0.3599 \\
Milk N & 0.103 & 0.105 & 0.0038 & 0.103 & 0.106 & 0.0038 & 0.6148 & 0.5891 \\
ENU & 24.57 & 23.33 & 0.740 & 23.22 & 24.68 & 0.7404 & 0.2453 & 0.1774 \\
UUN & 88.79 & 123.32 & 3.6853 & 108.29 & 103.82 & 3.6852 & 0.0001 & 0.3989 \\
MUN & 2.243 & 2.537 & 0.0908 & 2.365 & 2.415 & 0.0908 & 0.0304 & 0.7033 \\
BUN & 1.719 & 2.337 & 0.1156 & 2.0381 & 2.0170 & 0.1155 & 0.0009 & 0.8984 \\
\hline \hline
\end{tabular}

Key; DMI (dry matter intake), N (nitrogen), ENU (efficiency of nitrogen utilization \% (milk N/N intake *100)) UUN (urinary urea nitrogen), MUN (milk urea nitrogen), BUN (blood urea nitrogen). All values are in $\mathrm{kg}$ day $^{-1}$ with exception of UUN, MUN and BUN which are in $\mathrm{mmol}^{-1}$

Conclusion For cows used in this experiment at the production levels presented above there is no significant advantage to be gained in milk yield or milk $\mathrm{N}$ yield through the supplementation of low crude protein diets with ruminally protected methionine. The observed differences between forage types on urea levels in the bodily fluids and in particular urine may have environmental implications as there is less urea being excreted and therefore less potential for $\mathrm{NH}_{3}$ loss from dairy systems. Further more a reduction in urea syntheses also results in more energy being available for productive purposes in the dairy cow

Acknowledgements Funding for this research was provided under the National Development Plan, through the Research Stimulus Fund, administered by the Department of Agriculture, Fisheries and Food, Ireland

\section{References}

Mulligan et al., 2004, Journal of Dairy Science 87, 3451-3460

Write et al., 1998, Journal of Dairy Science 90, 908-917

Burke et al., 2007, Journal of Dairy Science 90, 908-917 